\title{
Lightning Bolt: ecologia de imagens, ruídos e sonoridades extremas ${ }^{1}$
}

\section{Resumo}

O artigo se detém, exclusivamente, no vídeo "Dracula Mountain", para a música homônima do duo de noise-rock norte-americano Lightning Bolt. A intenção, de fato, é bastante restrita: trata-se de descrevê-lo e problematizá-lo, pensando-o em contraponto à sonoridade e à performance musical da banda. Ao final, sustenta-se que o vídeo é sintoma e fruto de uma ecologia midiática muito particular e contemporânea, na qual produtos e gêneros (musicais e audiovisuais), bem como hábitos de consumo (musicais e audiovisuais), são refeitos e (re)potencializados, às vezes invertidos.

Palavras-chave:

Noise-rock, audiovisual, ecologia da mídia 


\title{
Lightning Bolt: an ecology of imagens, noises and extremes sounds
}

\author{
FABRÍCIO LOPES DA SILVEIRA
}

\begin{abstract}
The article is focused exclusively on the music video "Dracula Mountain", by north American noise-rock band Lightning Bolt. The aim is, in fact, sufficiently restricted: to describe the video and call it in question, considering it as a counterpoint to the band sonority and musical performance. At the end, we state that the video is both a symptom and a product of a very particular and contemporary media ecology, in which musical and audiovisual products and genres, as well as musical and audiovisual consumption habits are rebuilt and (re)potentialized, sometimes inverted.
\end{abstract}


Somente as pessoas superficiais não julgam pelas aparências.

O mistério do mundo está no visível, não no invisível.

Oscar Wilde

\begin{abstract}
Até
é meados dos anos 1990, "Lightning Bolt" era apenas uma conhecida marca de pranchas de surfe e surf wear. A imagem de um raio atravessando e preenchendo o vazio da letra "o" na palavra "bolt" ainda é bastante lembrada. Hoje, é também o nome de um conjunto de rock que vem compondo a "trilha sonora do inferno" 2 , tamanho o caos e o barulho que são capazes de instaurar. O grupo foi fundado em 1995, na cidade de Providence, Rhode Island - EUA, por dois colegas de faculdade, Brian Gibson e Brian Chippendale³, então estudantes de Design. Nesses quinze anos de carreira, gravaram cinco álbuns: o homônimo álbum de estréia (em 1999), Ride the Skies (2001), Wonderful Rainbow (2003), Hypermagic Mountain (2005) e Earthly Delights (2009).

A sonoridade do grupo é realmente extrema e impactante. É quase inaudível, provoca uma inquietação e um desconforto muito grande no ouvinte. De todo modo, ainda mantém estruturas que são próprias do rock (em sua padronização genérica). Trata-se de um conjunto que utiliza o modo clássico de instrumentação: baixo, bateria e guitarra. Ou melhor: utiliza uma variação mais compacta e sintética, ainda mais básica desse formato. São dois instrumentistas, baixo e bateria, apenas. Pouquíssimas vezes, na história do gênero (aceitando-se então o rock como um gênero muito específico, tranquilamente identificável no universo da música popular massiva [Cf. VILLAÇA, 2002; JANOTTI Jr., 2005]), foram registrados duos assim formados ${ }^{4}$. É necessário reconhecer que há, sem dúvida, um certo grau de dificuldade em produzir tanto barulho nessa conformação reduzida e enxuta. Os álbuns, em ge-
\end{abstract}


ral, foram recebidos com aprovação pela crítica especializada. Não raro, publicações como New Musical Express, The Guardian ou Sputnik Music tocavam no mesmo ponto: "Como é possível produzir tanto barulho com tão poucos recursos? Deve haver algum mérito nisso!"s. A reputação cult do grupo, o reconhecimento no cenário do rock experimental e de vanguarda, na última década, deu-se muito em função dessa espantosa formação ${ }^{6}$ (paradoxalmente, excessiva e mínima Figuras $01 \mathrm{e}$ 02).
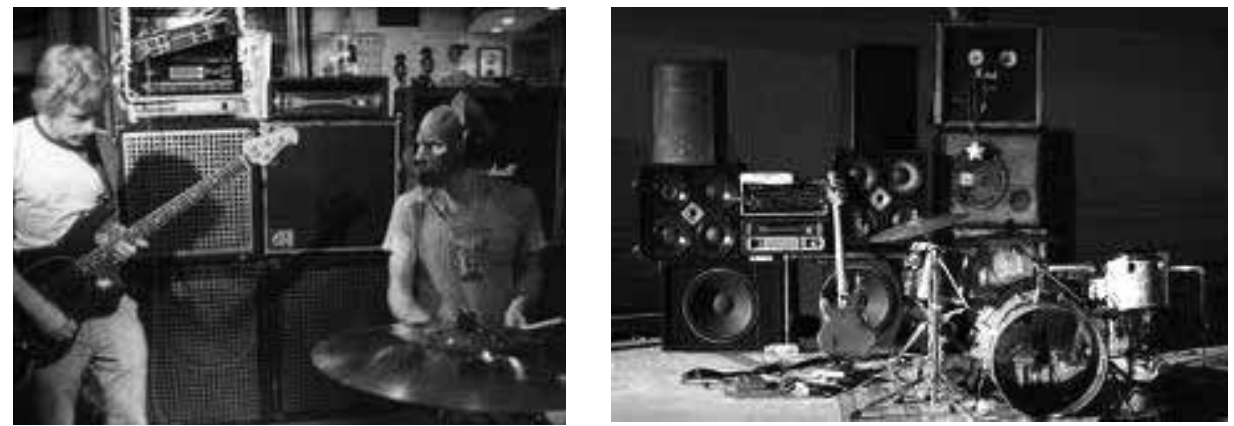

Figuras o1 $\mathrm{e} 02$ À esquerda, os dois Brians em ação. À direita, o kit de instrumentos e equipamentos utilizados.
As linhas de baixo, a cargo de Brian Gibson, soam como se fossem as guitarras e são, claro, bastante distorcidas e estridentes. A bateria não sustenta necessariamente uma base rítmica. É como se solasse continuamente. Não há uma batida marcada, mas pulsações, preenchimentos e solos constantes. De certa forma, o caráter frenético da música deve-se a essa performatização rítmica compulsiva, absurdamente inquieta. Brian Chippendale, o baterista, dificilmente pára. Ao longo das canções, é quase impossível vê-lo desacelerar, baixar a guarda por um momento, sossegar um pouco. Mas isso não quer dizer que esteja firmando um andamento, uma cadência regular e contínua. Há múltiplas quebras e múltiplas variações rítmicas, mantendo-se sempre o mesmo vigor e a mesma intensidade do barulho.

Além disso, há riffs (que, normalmente, seriam executados por uma guitarra). Aliás, há quase sempre uma série ou uma sucessão de riffs cortantes propostos e puxados pelo baixista. É interessante que não seja uma música apenas instrumental. Há vocalizações, embora não se possa dizer que exista canto. Talvez tenhamos até mesmo letra (saiba-se lá que temática, que assuntos sejam esses!7). Mais parece, na verdade, um balbucio, um grunhido pré-silábico. Brian Chippendale, o baterista, acumula os vocais. Entretanto, não se trata de um vocal com as 
funções habituais. Em alguns momentos, as vozes fazem eco, sublinham os riffs de baixo e os acentos tônicos dos compassos completos. Em outros, são peças sonoras moduláveis, dispostas aleatoriamente, elementos adicionais na produção de ruído (tanto melhor quanto mais e mais ruído houver). Seja como for, o que resta, invariavelmente, é aquilo que Roland Barthes (1990) chamou de "o grão da voz": não o canto, a letra ou a melodia, mas a pura presença vocal, a materialidade mesma daquela emissão, com sua expressividade indefinível e sua força ruidosa, compreendidos aí tanto as condições de um registro técnico - a dimensão medial da captura, da gravação e/ou da amplificação da voz de alguém - quanto também o rosto (ou melhor: as máscaras, como veremos) e o corpo daquele que "canta".

As máscaras utilizadas pelo baterista e vocalista Brian Chippendale - expostas abaixo (Figuras 03 a 08 ); sugeridas já numa das imagens acima - tornaram-se uma espécie de marca registrada. São obrigatórias durante as apresentações ao vivo. Foram desenhadas para que pudessem acomodar os microfones, mantendo-os sempre junto à boca. Por sua vez, os próprios microfones foram adaptados a partir de bocais de telefones antigos. Além do interessante efeito visual, essa "costura" máscara-microfone (aliás, trata-se literalmente de uma costura do microfone à máscara de tecido) dá maior agilidade ao músico, servindo à proposta estética do conjunto (afinal, também assim as vozes resultam mais abafadas, guturais, sussurradas e distorcidas) e substituindo os tradicionais pedestais colocados em linha, na frente do palco. Sem dúvida, esse arranjo permite (e cria as condições favoráveis para) a acelerada e vertiginosa estrutura rítmica das composições. Em suma: invenção e experiência estéticas - no universo do rock, fundamentalmente - decorrem de um engenho técnico-material. Aqui, ao menos, isso é evidente.
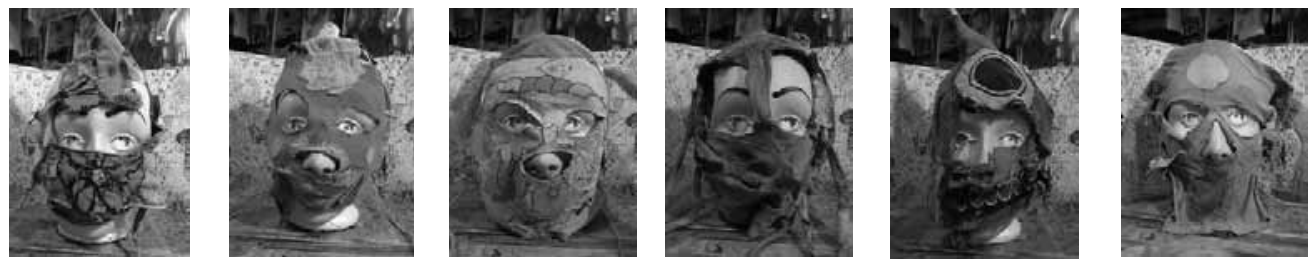

Mas há mais: ao substituírem os suportes dos microfones, tais máscaras auxiliam na drástica redução da parafernália de Figuras 03, 04, 05, 06, o7 e 08 As máscaras de Brian Chippendale palco. Assim, os equipamentos necessários às performances ao vivo reduzem-se ao mínimo indispensável: um compacto kit de bateria, um contrabaixo com um pequeno case de pedais de 
Figuras 09, 10, 11, 12, 13 e 14 Imagens das apresentações ao vivo.
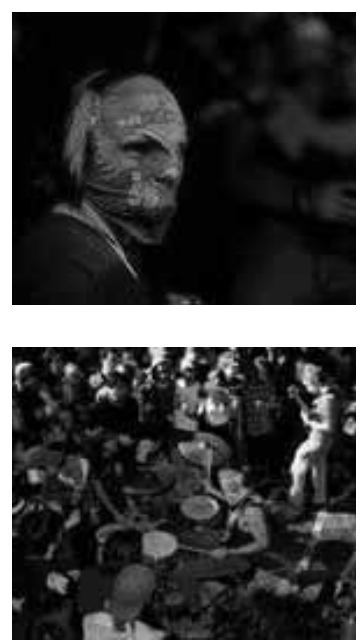

efeito e distorção - muita, mas muita distorção - e uma única, porém potente, coluna de caixas de som e amplificadores. Além das máscaras, é claro. Apenas isso. É a conjugação desse aparato técnico - desse pequeno conjunto de instrumentos e aparelhos - e dessa formação pocket que viabiliza as "guerrilla gigs”, como são chamadas as apresentações da banda. Até hoje, foram raras as vezes em que o grupo ocupou, de fato, um palco. Uma delas ocorreu recentemente, no festival Primavera Sounds 2009, em Barcelona. Geralmente, os shows ocorrem no chão, fora (ou em frente) do palco, em meio ao (e ao nível do) público, que se distribui, num tenso e movente semi-círculo, ao redor da banda. Durante o espetáculo, é comum que alguém da platéia, pressionado pela agitação das danças e dos empurrões, esbarre ou precise apoiar-se em algum dos músicos ou mesmo em algum dos equipamentos mais próximos. Em certas ocasiões, as canções precisam ser interrompidas para que a ordem se restabeleça (para que um fã mais afoito ou descuidado seja socorrido e possa colocar-se novamente em pé, para que outro, tateante, possa recuperar os óculos perdidos, para que as peças da bateria sejam reagrupadas e reposicionadas). No entanto, esses esbarrões - decorrência esperada do pogo e do headbanging ${ }^{8}$-, fazem parte do rito, são vividos com naturalidade, sem falar que acrescentam imprevisibilidade e risco, tornam ainda mais orgânicas e explosivas as aparições da bandaํ. Estamos sob o signo do caos. Ou quase isso (cf. imagens abaixo).
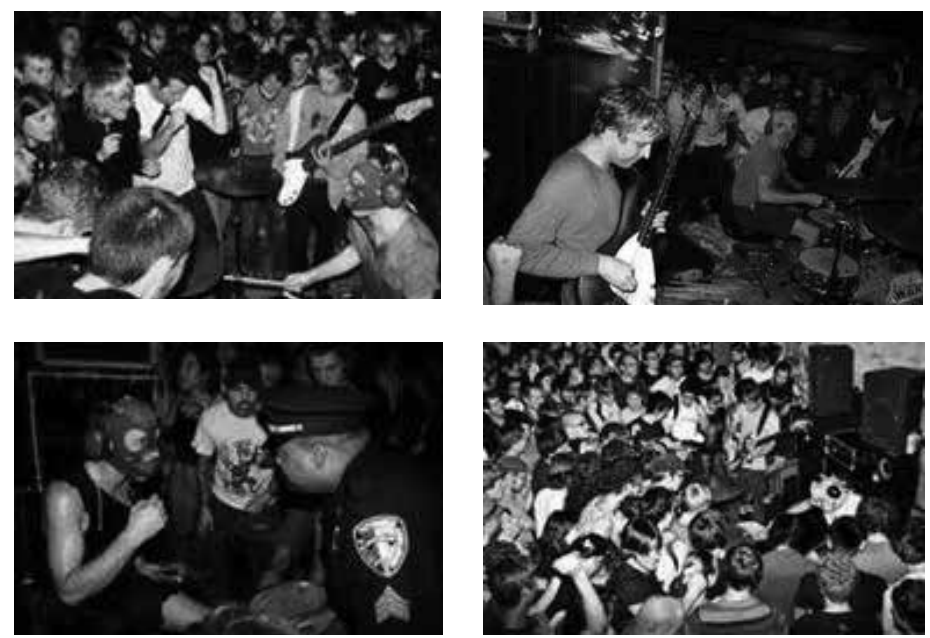

Musicalmente, o que se percebe, enfim, é uma organização no caos sonoro. Há momentos marcados, que provavelmente 
funcionam como estruturas de orientação, guias para a execução ao vivo. Há, portanto, composição. Há uma ordem rudimentar. Pode-se dizer inclusive que há refrões (até quando não há letra, é bom frisar). Ou seja: há uma costura de blocos. São construídas passagens mais ou menos nítidas entre um riff e outro.

"Dracula Mountain", música extraída do terceiro álbum da banda, Wonderful Rainbow (2003), exemplifica bastante bem esses traços estilísticos todos, lembrando muito a sonoridade de grupos como Butthole Surfers ${ }^{10}$. Lembra também - não poderia mesmo deixar de ser - algo do metal extremo e do hardcore (ou então algo entre esses subgêneros). Em virtude talvez da instrumentação convencional, a textura sonora não é necessariamente aquela do rock industrial, acentuada por baterias e instrumentos eletrônicos, ruídos e bases prégravadas. Ao contrário, a sonoridade é orgânica e analógica. Quanto às vozes, remetem às experimentações vocais de Mike Patton, em seus projetos solo ou à frente do grupo Fantômas" Há, inegavelmente, por trás da massa sonora, um padrão, uma estrutura arquitetônica da composição. Conforme Tim Scott (in DIMERY, 2007, p. 917), por exemplo, "embora não sejam exatamente 'melódicas' no sentido tradicional da palavra, canções como 'Crown of Storms' e 'Dracula Mountain' evidenciam sinais de uma estrutura musical mais reconhecível emergindo do ruído caótico".

É curioso especular também sobre o videoclipe ${ }^{12}$ da canção (aliás, é engraçado, pode ser até inapropriado chamá-la assim: “canção"!). Vemos imagens sujas se sobrepondo. À primeira vista parecem colhidas aleatoriamente, extraídas da grade da programação televisiva. Os efeitos empregados (efeitos de colorização, de granulação, de texturização, de branqueamento, de looping) são característicos da linguagem do vídeo. De tão básicos, são até precários. As imagens resultam vazadas. A sobreposição fica evidente. Sobrepostas, as cenas se alternam, ora menos, ora mais à frente. As imagens são desconexas, não possuem ligações ou vínculos aparentes. Por exemplo: nos segundos iniciais, vemos o trânsito e as vias públicas de uma cidade futurista, hipertecnologizada, repleta de máquinas voadoras e automóveis estilizados, tirados de um filme de ficção científica, possivelmente - embora não possamos identificá-lo com exatidão. Há então um corte. Em seguida, vemos quatro homens provavelmente às voltas com o assalto a um supermercado; com gestos e olhares ríspidos, tensos, ameaçadores, eles se dirigem ao funcionário do estabelecimento, braços erguidos ao alto. No fundo, simultaneamente, exibem-se as imagens de um mons- 
gênero musical, a própria estética do rock (BAUGH, 1994), são aqui testados, minados, colocados à prova.

É justa, é cabível, portanto, a suspeita de que uma música intensamente violenta e violentamente intensa - o "fundo musical de um acidente aéreo"14 -, cuja finalidade primeira parece ser o choque e a agressão, cujo efeito último é o de um espasmo, um mal súbito, esteja prevista, latente e contida na superfície até certo ponto plácida da cultura popular massiva.

De todo modo, é cedo demais para suposições tão gerais e para afirmações tão conclusivas. Aliás, o exame de um objeto trivial, aparentemente tão singelo (um vídeo de uma canção pop disponibilizado num site de compartilhamento) inviabiliza tais pretensões. É inegável, porém, que essa pequena e singularíssima peça possui suas complexidades e seus recônditos interessantes, deixando-se entrever aí certas dinâmicas atuais da prática musical (da cultura musical, seria correto dizer) no interior da cultura midiática. É válido então descrevêla e examiná-la de perto. Bem como é válido fazer (e testar) suposições a respeito.

O que mais chama atenção em "Dracula Mountain”? A música, o vídeo ou a inusitada combinação entre ambos (com sua potência intersemiótica, seus impactantes efeitos de ênfase e complementação mútua estabelecidos entre som e imagem)? O desconforto da experiência produz-se facilmente e é facilmente reconhecível. Parecem infindáveis aqueles cinco minutos! Poucos discordariam disso. Portanto, não precisamos citar essa desagradável sensação novamente. A radicalidade da concepção e da execução musicais ${ }^{15}$, bem como a adequação da edição de imagens a essa proposta estética (definida pela intensidade, pela sujeira e pela inquietude extremas, no limite do suportável) também já se encontram minimamente esboçadas. Por certo, tais recortes de análise são promissores e mereceriam estudos específicos, pormenorizados. Aqui, por enquanto, bastam.

No entanto, há algo que fascina e intriga ainda mais nessa peça audiovisual: o modo como "Dracula Mountain" se insere e é tecida - desdobrando-se, alongando-se, ressurgindo, tornando-se quase um quebra-cabeças, um insólito liquidificador - no interior de uma rede de referências muito próprias do circuito midiático.

Na verdade, ao menos formalmente, são poucos os registros audiovisuais do conjunto. Entre eles, estão os documentários The Power of Salad and Milkshakes (2003), dirigido por Peter Glantz e Nick Noe, e All Tomorrow Parties ${ }^{16}$ (2009), dirigido por Jonathan Caouette, com a colaboração coletiva de 
diversos outros aficcionados, cineastas e videomakers amadores. O próprio site da banda - www.laserbeast.com, já referido -, embora seja também um repositório de várias filmagens, apresenta-nos apenas imagens gravadas ao vivo, seqüências documentais de shows ou meros depoimentos, entrevistas diretas com os componentes da banda, algumas delas em programas de televisão, em canais segmentados, outras em estúdios de rádio ou em programetes produzidos originalmente para a web. Stricto sensu, não há videoclipes. Não há videoclipes tais como entendemos normalmente: curtas peças promocionais, num certo molde, numa certa gramática, assinadas e embaladas, geridas e gestadas no interior da indústria do entretenimento e dos conglomerados de comunicação (MACHADO, 2001; SOARES, 2005, 2006, 2007; JANOTTI Jr. e SOARES, 2008; CONTER, 2010).

Sendo assim, em função de suas (des)pretensões de mercado (do modo como aí se insere e se apresenta, num corte transverso, em paralelo, como quem dá de ombros) e mesmo em função do modo como é etiquetado e se coloca à disposição nos circuitos midiáticos (no YouTube, fundamentalmente), não se pode nem mesmo entender "Dracula Mountain" como um videoclipe oficial, autorizado e aceito enquanto tal. Poderíamos enquadrá-lo, por exemplo, até com certa facilidade, como um produto pertencente à "cultura do spoof" (FELINTO, 2008). Também não estaria distante das práticas de fansourcing (AMARAL, 2010). Ou seja: trata-se de algo confeccionado por um fã, a partir de imagens já produzidas, obtidas com outros propósitos, junto a outras fontes, em outras circunstâncias; trata-se de algo que não é reconhecido (ou que não é de pronto reconhecido, ao menos) como intencionalmente concebido e aprovado pelos músicos, após considerarem as pretensões estéticas que alimentam, a virtual obtenção de determinados capitais subculturais, as projeções de carreira, os posicionamentos estratégicos visados nos meandros da indústria fonográfica, etc. Nada disso.

O que temos, em síntese, é uma obra "pirata", um videoclipe "genérico" ${ }_{17}$, que se apropria e se vale, inadvertidamente, de um acervo de imagens correntes no universo da cultura pop. E "Drácula Mountain" não é o único exemplar dessa videografia não-oficializada, à margem da margem. Como outros - scratch vídeos, vídeo samples -, é feito das franjas, da reciclagem de um certo lixo audiovisual. Ocorre aqui um modo de processamento cultural muito típico da atual conjuntura das mídias, que referenda e corrobora, inclusive, aquilo que Andrew Keen (2009) chamou de "culto do amador"18. 
Entretanto, justamente por isso, justamente por assumirse como é - amador e "pirata" -, este vídeo se vê alçado à curiosa condição de um "mais-que-pirata", altamente afinado ao "faça você mesmo", ao veio crítico, insubordinado e selvagem, pouco paciente em relação às convenções normativas e às exigências burocráticas, que são suscitados pela proposta musical do conjunto. $\mathrm{O}$ fato de que seja assim o torna mais representativo, mais coerente e mais digno, não só no que diz respeito à música, ela mesma, mas em relação à atitude toda, ao ideário e aos valores professados, ao punch e ao "elã vital" cultivados com afinco pela banda. Seja como for, a regra é clara: o máximo de perturbação com o mínimo de recursos - muito impacto, pouquíssimos instrumentos.

Contudo, essa coerência geral entre sonoridade, performance e uma ecologia ou um tecido de imagens não se faz sem alguns pequenos paradoxos, "paradoxos de tom menor", pode-se dizer. A conjunção harmônica - e não é irônico haver aqui harmonia? - desses dados visuais e sonoros se apóia nessas tensões secundárias, nessas rugosidades presentes, até mesmo, no entrelaçamento das bases expressivas, na amarra e no manejo dos materiais empregados. Há, por exemplo, um discreto contraponto entre a dimensão ou a natureza digital das imagens, imagens maleáveis, fundadas na pós-produção, definidas e encontradas num tipo informal de pesquisa de arquivo, e a dimensão analógica, ao vivo, situacional, em ato, da execução da(s) música(s). Por um lado, uma replicabilidade, uma anotação refeita e outra vez refeita (uma paródia, uma paródia de uma paródia - como veremos); de outro, a pulsão e a pulsação de uma presença. Na visualidade, traços pós-modernos (remixabilidade, citações, citações de citações, carregamento e excesso semióticos); na sonoridade, traços pré-modernos (trabalho orgânico, artesania, espontaneísmo tribal, texturas low-fi e low-tech, irreprodutibilidade técnica).

Mas essa pequena disjunção não vem só, nem isolada. A ela somam-se outras. É muito sugestivo que "Dracula Mountain" tenha sido incorporada - numa esforçada versão cover - ao repertório do grupo britânico Muse, um sucesso pop, vendável e radiofônico ${ }^{19}$. Sugestivo também é o fato de que a cantora islandesa Björk, mundialmente conhecida, tenha convidado Brian Chippendale para acompanhá-la nas gravações de uma faixa para um projeto beneficente (a Nattura Environmental Campaign). A despeito de toda radicalidade, como vemos, o mainstream sempre se avizinha, sempre acena com suas ofertas, homenagens e encantos. Insinua-se aqui 
um princípio - muito, muito tímido - de dissolução dessas categorias e desses lugares antitéticos que são o underground (o mercado subterrâneo da música, onde experiências como Lightning Bolt podem aflorar) e o mainstream (o show biz, o mundo instituído da música)? Nem mesmo "Dracula Mountain", com toda sua contundência, estaria imune a essas inesgotáveis tensões (entre autenticidade x cooptação, entre singularidade criativa x padronização massiva)? Ao que parece, nem mesmo "Dracula Mountain"...

Além disso, é difícil fixar o trabalho de Fred J. Henzel, o ("diretor") responsável pelo vídeo. Envolvido em projetos artísticos autorais, e tendo realizado outros trabalhos audiovisuais no cenário da música alternativa - tais como os vídeos "Hyenas laughing in mountain", para Kixly, e "Opposite corners", para 310, $\operatorname{ambos}^{20}$ vinculados à música eletrônica e à ambient music (e, aliás, plasticamente muito similares) -, Henzel parece conceber "Dracula Mountain" como um produto artesanal, quase como um tributo afetivo, como se fosse um experimento e uma mera brincadeira com um manancial de imagens e com uma certa memória da cultura trash midiática. Inclusive, num de seus comentários postados no YouTube, junto ao vídeo, Henzel menciona os softwares utilizados para realizá-lo. Diz ele:

First, I downloaded a bunch of clips from youtube using a program called Tube TV. Then I used FinalCut Express, which was on my computer when I bought it used. I repeated the segment of the Steven Segall commercial many times always starting it over when the music started over.

Além de explicitar o próprio processo produtivo - o que salienta, em alguma medida, seu caráter informal, diletante e amadorístico -, o comentário de Fred Henzel dá uma ótima chave para a leitura do vídeo: refere-se ao "Steven Segall (sic) commercial", às imagens que foram retiradas de um comercial de televisão estrelado pelo ator para a marca de refrigerantes Mountain Dew. "Do the dew" era o mote da campanha, levada ao ar em 1993. Nela, Seagal parodia a si mesmo. A peça publicitária faz referência ao filme Hard to Kill (Difícil de Matar, de 1990), em que Seagal interpreta o personagem Mason Storm. Mais exatamente, cita e reproduz a cena de uma briga entre Storm e uma gangue de rua, dentro de uma loja de conveniências. O encontro ocorre mais ou menos por acaso, é um encontro fortuito, sem conseqüências diretas para a narrativa e a trama do filme (antes, serve para enfatizar a destreza, as ha- 
bilidades e o caráter de Mason Storm, um policial que retorna do coma para vingar as mortes do filho e da esposa ${ }^{21}$. Após enfrentar e vencer, com golpes de Aikido, muita paciência e violência explícita, cada um dos quatro oponentes (armados e rudes - estereotipados, portanto - até os dentes), Storm retoma sua jornada de herói como se nada houvesse ocorrido, mantendo a calma, a classe, o terno impecavelmente limpo e o cabelo preso num irretocável rabo-de-cavalo. Uma das mais clássicas cenas de luta dos filmes de ação da década de 1990! O comercial televisivo adere a ela, refazendo-a.

Entretanto, não estamos diante de uma citação, apenas. Não se trata nem mesmo de um trocadilho ou de uma paródia visual, tão somente. Estamos diante de duas citações, uma paródia dentro de uma paródia, no mínimo. Trata-se de uma cascata de referências cruzadas e meta-citações, um mosaico de textos sobrepostos e associados, tendo em vista que Lightning Bolt é também a marca de um energy drin ${ }^{22}$ cujo garoto-propaganda é - santa coincidência! - o próprio Steven Seagal. É dele o rosto que vemos junto ao rótulo, posicionado junto à marca, no verso (ou no dorso) da lata em que a bebida é vendida. Há um detalhe ainda mais impressionante (ou mais bizarro, se não for dolorosamente cômico): o drink é produzido, distribuído e comercializado pela Steven Seagal Enterprises! Em termos mais simples: Seagal é o dono da empresa! Seagal é o chefe!

Fecha-se então o tortuoso círculo. "Dracula Mountain" e Lightning Bolt encontram-se presos numa particularíssima cadeia de textualidades e formas midiáticas, cuja mais completa tradução é a imagem eletrizante do raio, com sua incontida e aterradora força natural. Uma imagem, aliás, repleta de significados - descarga elétrica, luz intensa e viva, energia temida e admirada são apenas alguns dos sentidos que carrega. Dado o modo como reincide, surgindo e ressurgindo em diferentes culturas, em diferentes épocas, como nos mostram alguns estudos de Aby Warburg (WARBURG, 2008; WARBURG apud BAITELLO Jr., 2010) ${ }^{23}$, ou no coração mesmo da moderna cultura pop, vide as versões recorrentes do raio em artistas como David Bowie, AC/DC ou Lady Gaga (cf. imagens a seguir), pode-se até dizer que contém traços de uma imagem-mítica, é a máscara, bem como a sobrevivência, de uma ancestralidade.

De forma mais comedida - para então finalizarmos -, cabe apenas reconhecer que, além do vídeo em causa, o próprio nome do conjunto pode ser lido como sintoma e fruto de uma ecologia midiática, com seus fluxos e refluxos, os rebatimentos que lhe caracterizam. É como se tivéssemos um arco 
Figuras 17, 18, 19, 20, 21 e 22 Distintas aparições do raio no universo da cultura pop.

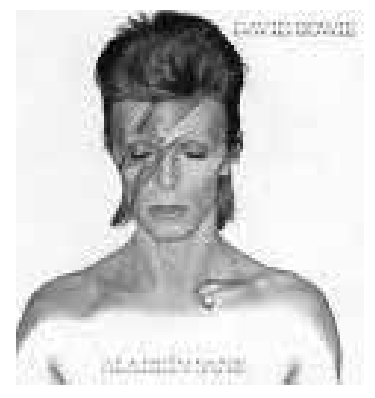

que tem numa de suas extremidades a marca Lightning Bolt (a marca de surf wear, bem entendido) e, na outra, o energy drink Lightning Bolt (associado à cativante e desafiadora figura de Steven Seagal [cf. abaixo]). De algum modo, Lightning Bolt, a banda, seria aí um metafórico termo médio, a simbolização de um encontro, uma continuidade ou uma junção, uma partícula aditiva que, simultaneamente, ironiza e digere, tensiona, transcende e radicaliza aquilo que une.
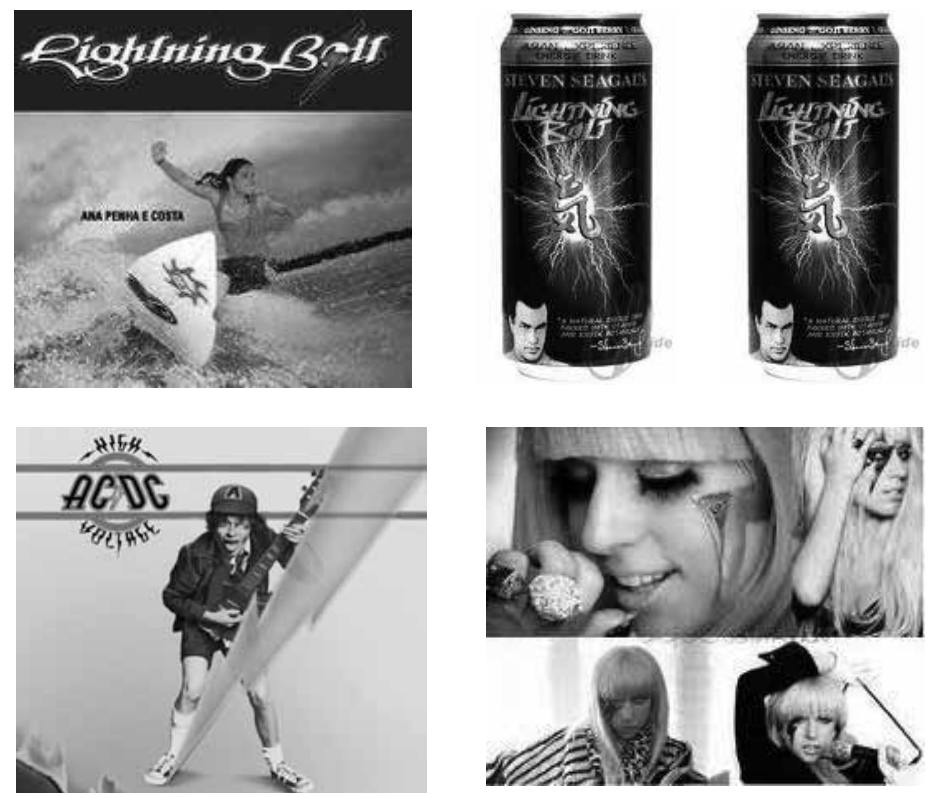

\section{Referências}

AMARAL, Adriana. Práticas de fansourcing: estratégias de mobilização e curadoria musical nas plataformas musicais. in: SÁ, Simone Pereira de (org.). Rumos da Cultura da Música. Negócios, estéticas, linguagens e audibilidades. Porto Alegre: Sulina, 2010, p. 139-163.

BAITELLO Jr., Norval. A Serpente, a Maçã e o Holograma. Esboços para uma Teoria da Mídia. São Paulo: Paulus, 2010.

BARTHES, Roland. O grão da voz. in: BARTHES, Roland. $O$ Óbvio e o Obtuso. Ensaios Críticos III. Rio de Janeiro: Nova Fronteira, 1990, p. 237-245.

BAUGH, Bruce. Prolegômenos a uma estética do rock. Novos Estudos CEBRAP, n.38, São Paulo, março de 1994, p. 15-23. 
COELHO, Sandra; ESTEVES, Ana Camila. A narrativa autobiográfica no filme documentário: uma análise de Tarnation (2003), de Jonathan Caouette. Doc On-Line, n.o9, dezembro de 2010, p. 19-42. Disponível em <http://www.doc.ubi.pt>. Acesso em 26/o1/2011.

CONTER, Marcelo. Potências de videoclipe no cinema e no vídeo. in: KILPP, Susana; ROSÁRIO, Nísia Martins do; SILVA, Alexandre Rocha da (orgs.). Audiovisualidades da Cultura. Porto Alegre: Entremeios, 2010, p. 213-233.

CASPARY, Costa; MANZENREITER, Wolfram. From subculture to cybersubculture? The japanese noise alliance and the internet. in: GOTTLIEB, Nanette; McLELLAND, Mark (eds). Japanese Cybercultures. New York: Routledge, 2003, pp. 6o-74.

DIMERY, Robert (org.). 1001 Discos para Ouvir Antes de Morrer. Rio de Janeiro: Sextante, 2007.

FELINTO, Erick. Videotrash: o YouTube e a cultura do "spoof" na internet. Galáxia. Revista transdisciplinar de Comunicação, Semiótica e Cultura. Programa de Pós-Graduação em Comunicação e Semiótica da PUC - SP, n.16, São Paulo, dez./2008, p. 33-42.

JANOTTI Jr., Jéder. Dos gêneros textuais, dos discursos e das canções: uma proposta de análise da música popular massiva a partir da noção de gênero midiático. Trabalho apresentado no XIV Encontro da COMPÓS - Associação Nacional dos Programas de Pós-Graduação em Comunicação. Rio de Janeiro, junho de 2005, p. 12.

JANOTTI Jr., Jéder; SOARES, Thiago. O videoclipe como extensão da canção: apontamentos para análise. Galáxia. Revista transdisciplinar de Comunicação, Semiótica e Cultura. Programa de Pós-Graduação em Comunicação e Semiótica da PUC - SP, n.15, São Paulo, junho/2008, p. 91-108.

KEEN, Andrew. O Culto do Amador. Como blogs, MySpace, YouTube e a pirataria digital estão destruindo nossa economia, cultura e valores. Rio de Janeiro: Jorge Zahar, 2009.

MACHADO, Arlindo. A Televisão Levada a Sério. São Paulo: Senac, 2001.

PEREIRA, Vinícius Andrade; CASTANHEIRA, José Cláudio; SARPA, Rafael. Simbiotecnoises: ruídos extremos na cultura do entretenimento. in: SÁ, Simone Pereira de (org.). Rumos da Cultura da Música. Negócios, estéticas, linguagens e audibilidades. Porto Alegre: Sulina, 2010, p. 189-208.

SOARES, Thiago. O videoclipe como articulador dos gêneros televisivo e musical. Trabalho apresentado ao GT Audiovisual, do IX Congresso Brasileiro de Ciências da Comunicação da 
Região Nordeste (Intercom), Salvador - Bahia, o7 a o9 de junho de 2007, p. 13.

. Por uma metodologia de análise mediática dos video-

clipes: contribuições da Semiótica da Canção e dos Estudos Culturais. São Leopoldo - RS, Universidade do Vale do Rio dos Sinos, UNIrevista - Vol. 1, nº 3: (julho 2006), p. 11.

. O videoclipe no horizonte de expectativas do gênero musical. Revista e-Compós - Revista da Associação Nacional dos Programas de Pós-Graduação em Comunicação. Disponível em http://www.compos.com.br/compos, dezembro de 2005, p. 18.

VILLAÇA, Renato Costa. O rock e as bases de uma cultura musical pop. Trabalho apresentando no XI Encontro Anual da Compós, UFRJ, Rio de Janeiro - RJ, realizado entre o4 e o7 de junho de 2002. Disponível em <http://www.compos.org.br/ data/biblioteca_119.PDF>. Acesso em 21/o1/2011.

WARBURG, Aby. El Ritual de la Serpiente. Madrid: Sexto Piso, 2008.

\section{Filmografia}

Hard to Kill. Dir. Bruce Malmuth. Warner Home Vídeo. 1990. DVD.

The Power of Salad and Milkshakes. Dir. Peter Glantz e Nick Noe. Load Records. 2003. DVD.

Tarnation. Dir. Jonathan Caouette. Wellspring Media. 2003. DVD.

All Tomorrow's Parties. Dir. Jonathan Caouette. Warp Films. 2009. DVD.

\section{Discografia}

Lightning Bolt. Lightning Bolt. Load Records. 1999. CD.

Ride The Skies. Lightning Bolt. Load Records. 2001. CD.

Wonderful Rainbow. Lightning Bolt. Load Records. 2003. CD. Hypermagic Mountain. Lightning Bolt. Load Records. 2005. CD.

Earthly Delights. Lightning Bolt. Load Records. 2009. CD. 
2. São palavras de Charles Pilger, obtidas em depoimento pessoal. Pilger foi colaborador do Gordurama, extinto zine eletrônico dedicado à cena da cultura independente e alternativa no Rio Grande do Sul.

3. A coincidência dos nomes - os dois Brians, essa própria pronúncia "both Brians" - é sugerida já no MySpace da banda: http://www.myspace.com/ lightningboltbrians.

4. Bandas como White Stripes e The Kills (além de outras, menos conhecidas, como Two Galants, Golden Animals, Japandroids e The Evens - listadas na plataforma LastFM, no indexador "Band of two men") possuem formações apenas assemelhadas. Acrescente-se ainda o projeto de John Paul Jones e Diamanda Galás, no álbum The Sporting Life (1994). Aqui, no caso, a ausência da guitarra - um instrumento-ícone, tratando-se de rock - é largamente compensada pelos fraseados groove do ex-baixista do Led Zeppelin e pela exuberante performance cênico-vocal da cantora grega. Duos de baixobateria, exclusivamente, são mais raros. Podemos citar, por exemplo, os japoneses do Ruins e os norte-americanos do Om. Nenhum deles, contudo, é tão impressionante e ensurdecedor.

5. Boa parte dessa repercussão jornalística pode ser conferida no site http:// www.laserbeast.com. Ali encontramos também fotos, vídeos diversos e a agenda de shows.

6. Na formação original constava ainda o guitarrista e vocalista Hisham Bharoocha. No entanto, antes mesmo do lançamento do primeiro álbum, o conjunto já havia se estabilizado como um duo. Com Bharoocha, há um único registro: a faixa "Revenge", na compilação Repopulation Program, de 1996 (EUA, Load Records).

7. Como exemplo dessa poética, vale conferir a letra de "Dracula Mountain", música que iremos destacar ao longo do texto. Basicamente, é o seguinte:

"See you in the evening/ See you in the dawn/ See you all the daylight/ Then in the beyond". Informações adicionais obtidas no Wikipedia sustentam que "Lightning Bolt's lyrics, when decipherable, are generally tongue-in-cheek, covering such topics as fairy tales, heavy metal clichés, terrorism, anarchy and superheroes. They delve occasionally into more political subjects, such as the anti-Bush 'Dead Cowboy', from Hypermagic Mountain”. Cf.: http:// en.wikipedia.org/wiki/Lightning_Bolt_(band).

8. O pogo é a tradicional dança punk. Consiste em andar (ou correr) em círculos como se estivéssemos chutando o ar. O headbanging é uma prática associada aos fãs de heavy-metal: é o ato de balançar a cabeça (e os cabelos compridos, preferencialmente), para cima e para baixo, no ritmo das músicas. O que se vê em shows do Lightning Bolt são variações dessas práticas, ora alternadas, ora hibridizadas. Âs vezes, tornam-se impraticáveis devido à sonoridade sem precedentes do grupo. A simulação de surtos epiléticos também compõe o repertório de técnicas corporais com o qual o público dança e se diverte.

9. O documentário The Power of Salad and Milkshakes (2003), dirigido por Peter Glantz e Nick Noe, registra inúmeras dessas cenas. Em 2001, Glantz e Noé acompanharam a turnể americana da banda. Foram dezenove apresentações, em dezenove cidades. Uma dessas apresentações ocorreu na cozinha de uma residência (!). Não surpreende que a Polícia tenha comparecido para antecipar o encerramento do evento.

10. Butthole Surfers é um dos mais representativos e queridos grupos do college rock e da cena underground norte-americana dos anos 1980-90. Hairway to Steven (1988) e Electriclarryland (1996), por exemplo, são álbuns memoráveis.

11. Mike Patton ficou conhecido como vocalista do grupo Faith No More, que obteve reconhecimento da crítica, boa visibilidade midiática e considerável 
desempenho mercadológico, com sua fusão de funk, rap e metal, desenvolvida ao longo da década de 1990. Entre seus trabalhos solos, estão os álbuns Adult Themes for Voices (1996) e Pranzo Oltranzista: Musica da Ravola per Cinque (1997). Ambos são experiências com colagens sonoras, ruídos vocais, diversos barulhos corporais e pouca instrumentação (sobretudo o primeiro). Atualmente, entre seus diversos projetos musicais, está o grupo Fantômas. Cf. Fantômas (1999), Director's Cut (2001), Delirium Cordia (2004) e Suspended Animation (2005).

12. O vídeo encontra-se disponível em http://www.youtube.com/ watch? $=m_{7}$ fVK1mA2zg. Em 04/o2/11 contava com 35.307 views.

13. Segue-se o diálogo entre esse suposto "pregador midiático" e sua audiência, os fiéis ali presentes: “- What day is today?", pergunta ele. "- Friday", responde o coro. “- What Day is that?”, continua. “- The Global Jerusalém Day”, reagem outra vez os devotos do auditório. “- Yes, is the Global Jerusalém Day”, prossegue o pastor, antes de alongar-se: "the day all the precious iranians go out to protect the oppressed, defenseless palestinians. Children of Palestine! We are with you! You don't have home, school or food and can't live property... We love you. Yes. Today is the Global Jerusalém Day. We await the Day. Palestine will be liberated. On the Lord's land, everyone has a home on the Lord's land and everyone loves his home very much. Nobody has the right to stay in someone else's home and to consider it his own. Even with a tiny stone, the palestinian child goes out to fight for his country. He is waiting to shed his blood for his country and expel the enemy even at the cost of his life. Everyone has a home on the Lord's land. Everyone has a home on the Lord's land".

14. Essas são palavras de Caio Bruno do Carmo, em depoimento pessoal. Caio Bruno é jornalista, músico e fotógrafo, ex-pesquisador Pibic-CNPq/UFPI no projeto "Escola de Palo Alto e os paradoxos comunicacionais", conduzido pelo prof. Dr. Gustavo Said junto ao Departamento de Comunicação - UFPI.

15. No campo da Comunicação, ainda são poucos os estudos empíricos pontualmente dedicados àquilo que poderíamos chamar de "sonoridades extremas", casos singulares situados muito além (ou muito aquém) das prerrogativas de mercado e das conformações dos gêneros e subgêneros usuais da música popular massiva. Dentre os estudos disponíveis, podemos citar, por exemplo, Caspary e Manzenreiter (2003) e Pereira, Castanheira e Sarpa (in SÁ, 2010).

16. Caouette concebeu e dirigiu também sua auto-biografia cinematográfica, Tarnation (EUA, 2003). O filme foi produzido por Gus Van Sant e foi exibido nos prestigiados festivais de Cannes e Sundance, em 2004. Premiado pela National Society of Film Critics e pelo Independent Spirits Award, tornou-se objeto de culto no circuito do atual cinema independente norte-americano (Cf. COELHO e ESTEVES, 2010). Em All Tomorrow Parties, Caouette responsabilizou-se pelo corte final do documentário, editando e montando as cenas registradas, em diferentes bitolas, por dezenas de fãs e músicos participantes das diversas edições do festival homônimo. All Tomorrow Parties (ATP) é um festival itinerante de música alternativa, realizado anualmente, a partir de 2000 . Dedica-se ao mapeamento do cenário contemporâneo e das mais novas tendências da música underground. Na edição de 2004, Lightning Bolt foi uma das atrações.

17. Conforme Soares (2005), Janotti Jr. e Soares (2008), Fred Zero Quatro, vocalista e guitarrista da banda pernambucana Mundo Livre S/A, em entrevista dada ao documentário Vamos Fazer um Clipe? (2004), referiu-se aos videoclipes feitos "fora dos esquemas" das grandes gravadoras como "clipes genéricos" - numa alusão irônica aos "medicamentos genéricos". Aqui, sem dúvida, o termo é perfeitamente adequado. Em tempos de internet, Twitter, Facebook, MySpace e YouTube - tempos pós-TV (e, conseqüentemente, pósMTV) -, caberia indagar sobre a força comunicacional, a constituição técnica, o apelo estético e os vínculos sociológicos acionados por esses produtos.

18. Como dissemos, temos propósitos restritos: priorizamos a descrição e a problematização (incluindo-se aí as primeiras linhas interpretativas) do vídeo feito para a música "Dracula Mountain". Entrar no mérito, avaliar a 
consistência e o alcance teóricos das formulações sobre o "culto do amador", a "cultura do spoof" e as práticas de fansourcing (apresentadas e detalhadas, respectivamente, em Keen [2009], Felinto [2008] e Amaral [2010]), são ações que estão fora dos limites operacionais que nos impusemos. Por certo, essas discussões (juntamente com outras - a conceituação de "ecologia da mídia" e "performance", por exemplo) serão feitas no prosseguimento dos estudos.

19. Em meados de 2010, a banda já tinha vendido mais de 11 milhões de álbuns em todo o mundo. Cf.: http://en.wikipedia.org/wiki/Muse.

20. "Hyenas laughing in mountain", de Kixly, e "Opposite corners", de 310, podem ser facilmente visualizados no YouTube. É interessante perceber as similaridades (técnicas, formais, estéticas) entre esses vídeos. Não só entre eles, mas também entre eles (juntos ou não) e "Dracula Mountain". O efeito estético, contudo, é BASTANTE DIVERSO.

21. Recuperado, Storm acaba envolvendo-se com sua enfermeira (interpretada por Kelly LeBrok) e descobre que seu filho, de fato, não havia morrido. Esses acontecimentos só vêm apimentar a narrativa.

22. Segundo o site da empresa - www.lightningdrink.com -, trata-se do único energy drink $100 \%$ natural, feito à base de botânica e vitaminas exóticas, baga tibetana de Goji, cordyceps asiático, vitamina B, ginseng, guaraná, erva-mate e suco de cana de açúcar. Consta que foi o próprio Seagal quem elaborou a receita.

23. Por volta de 1895 , Warburg observou o ritual da serpente, realizado entre os índios Pueblo, do Novo México. Na ocasião, chamou-lhe atenção a gama de significados de que se revestiam essas duas entidades: o raio e a serpente. Por vezes, raios e serpentes eram confundidos, equivalentes, tomados um pelo outro. Em algumas representações, os raios eram serpentes atiradas dos céus. Reportando-se à experiência de Warburg, Baitello Jr. (2010, p.112) diz que se trata, portanto, "de uma figura presente nas mais diversas mitologias, a do relâmpago e do raio, divindades de extremo poder ou ferramentas de deuses de grande poder, que contaminam com seus significados míticos os mundos transmitidos pelos meios terciários".

Recebido em: 08/12/11

Aceito em: 03/02/12

\section{FABRÍCIO LOPES DA SILVEIRA}

fabriciosilveira@terra.com.br.

Graduado em Jornalismo pela Universidade Federal de Santa Maria (1995), Mestre em Comunicação e Informação pela Universidade Federal do Rio Grande do Sul (1998) e Doutor em Ciências da Comunicação pela Universidade do Vale do Rio dos Sinos (2003). Atualmente, é professor dos cursos de graduação e pós-graduação em Comunicação da Unisinos, em São Leopoldo - RS. Também já atuou vinculado à graduação e à pós-graduação em Design Estratégico, na mesma universidade. Em duas ocasiões, foi pesquisador convidado e professor visitante na Universidade Autônoma de Barcelona. É autor do livro O Parque dos Objetos Mortos. E outros ensaios de comunicação urbana (Porto Alegre: Armazém Digital, 2010). Em 2011, organizou o volume Pequenas Crises. Pesquisa em Comunicação e experiência estética (Porto Alegre: Modelo de Nuvem, 2011). 